\title{
Bernardo J. García García, Katrin Keller y Andrea Sommer-Mathis (eds.). De puño y letra. Cartas personales en las redes dinásticas de la Casa de Austria, Madrid, Iberoamericana, 2019, 413 págs.
}

Este volumen colectivo, que reúne una serie de estudios temáticamente relacionados, se inserta dentro de varias corrientes historiográficas que emergieron en los últimos años. En primer lugar, forma parte de los estudios sobre las relaciones dinásticas de las dos grandes ramas de la Casa de Austria que se formaron después del reinado de Carlos V en el Sacro Imperio, que a la vez reinó como Carlos I en las coronas de Castilla y Aragón. Tras su abdicación (1555/1556) y posterior muerte (1558), sus dominios se dividieron entre la rama española a partir de su hijo Felipe II y la rama austriaca o alemana con su hermano Fernando I. Ahora bien, las relaciones entre ambas ramas en el siguiente siglo y medio tuvieron sus altibajos, pero siempre fueron intensas y se confirmaba la alianza con matrimonios mutuos en casi todas las generaciones. Entre los estudios actuales destacan la obra La dinastía de los Austria de tres tomos, editada por José Martínez Millán y Rubén González Cuerva (2011).

La segunda corriente en que se inserta esta obra es la historia de la nobleza femenina, que históricamente ha sido descuidada al lado de la nobleza masculina, con excepción de las pocas reinas titulares, como Isabel la Católica. En este sentido, obras como la colección Queenship and Power que cuenta ya con unos 50 volúmenes, tratan de enmendar esta situación, al analizar reinas consortes en toda Europa e incluso fuera de ella. Para el caso de los Habsburgo, se puede mencionar además la reciente obra colectiva
Mujeres en la Corte de los Austrias, editada por María Leticia Sánchez Hernández.

Finalmente, esta obra forma parte de las investigaciones acerca de las cartas, correspondencia y epistolarios. Si bien esta área cuenta con una larga tradición y ediciones de cartas desde hace ya más de un siglo atrás, lo cierto es que, precisamente, para el caso de las mujeres ha quedado mucho trabajo pendiente. En concordancia con la percepción tradicional del rol de la mujer, limitada al ámbito privado, se han interpretado sus correspondencias también casi únicamente en este sentido. Sin embargo, como se ha destacado ya para el caso de los varones de los siglos XVI y XVII, los ámbitos públicos y privados no son realmente separables en aquella época. Lo anterior, por lógica debiese aplicar también a las mujeres de nobleza y realeza, suposición que los editores toman como punto de partida.

Para explicar brevemente el título, este hace referencia a que las cartas fueron escritas personalmente por las remitentes y no por secretarios. Esto es importante de destacar, ya que la redacción con la propia mano era considerada como una señal de respeto y estimación hacia el destinatario. En este sentido se entiende también la referencia que hace Bernardo J. García García en su capítulo sobre la correspondencia de la infanta Isabel Clara Eugenia, quien en las cartas a su hermano Felipe III excusa a su marido, el archiduque Alberto por 
no contestar las suyas con la propia mano, cosa que le sería impedida por la avanzada gota que sufría.

Las contribuciones se dividen en tres apartados, aunque debemos adelantar que hay varios temas tan transversales y fundamentales que aparecen en cualquiera de los tres. El primero lleva por título general "Aspectos personales en la correspondencia de los Austrias" y cuenta con cuatro capítulos. Dos de ellos, se enfocan en las relaciones entre hermanos, María de Hungría con sus hermanos Carlos V y Fernando I, por una parte, e Isabel Clara Eugenia con su hermano Felipe III, ambos hijos de Felipe II. En los otros dos casos son esposas y su correspondencia con sus maridos, Catalina Micaela (también hija de Felipe II) con Carlos Manuel I de Saboya y la infanta María Ana (hija de Felipe III) con su marido, el emperador Fernando III.

En general, hay dos temas bastante transversales y predominantes. Por una parte, los avisos de nacimientos y muertes de familiares y, por otra parte, la cuestión de salud de los corresponsales y sus cercanos. Si bien, ambos temas parecen muy personales, lo cierto es que también tienen una alta connotación política, ya que se trata de asuntos dinásticos de primera importancia. La búsqueda de hijos, especialmente un heredero varón, era una cosa primordial para cada matrimonio real y su cumplimiento estaba entre sus principales deberes. También la salud o la falta de ella e incluso la muerte tienen implicaciones dinásticas importantes, ya que, de la supervivencia del propio monarca, de su esposa y de sus hijos podía depender la continuidad dinástica, la cual constituía el deber principal frente a la familia.
Las cartas entre Catalina Micaela y su marido contienen, además, otro tema principal que eran las prácticas religiosas. Si bien las prácticas en Turín no eran fundamentalmente distintas a las de Madrid y la infanta se adaptó en varios sentidos a ellas, seguía habiendo diferencias entre los dos, que eran también objeto de cartas. El asunto aparece también en la relación entre Fernando III y María Ana, entre quienes, además de otras cosas, hubo discusiones sobre si la infanta podía llevar su confesor capuchino a Viena o si debía aceptar que fuera un jesuita austriaco, como deseaba su esposo.

El segundo bloque se intitula "Redes familiares e influencia política en la Casa de Austria" y contiene en total cinco contribuciones. Todas las mujeres protagonistas de este apartado pertenecen a la rama austriaca de los Habsburgo. Como indica Katrin Keller en su capítulo, las cartas de las nobles alemanas se han estudiado mucho menos en comparación con otros lugares. Además, contiene el único capítulo protagonizado por un varón, concretamente el archiduque Leopoldo Guillermo y su correspondencia con su hermano, el emperador Fernando III.

Lo que llama la atención de esta última contribución, escrita por Pia Zachary, es que las cartas analizadas se podrían calificar efectivamente como privadas, ya que contienen diversas emociones, algo muy poco común entre los nobles, especialmente varones, de aquella época. Los casos analizados de las mujeres en este apartado, en cambio, nos muestran que existían verdaderas redes transnacionales de mujeres que intercambiaban 
informaciones de todo tipo, pero sin duda alguna, no solamente privada.

Así, María, nieta de Fernando I y casada con el archiduque Carlos, mantenía una clientela en Graz, Cracovia, Múnich, Para e incluso, hasta cierto alcance, en Madrid, clientela que le proveía con las novedades que ocurrían en estas capitales. Un ejemplo destacado de estas redes constituye el Convento de las Descalzas Reales, donde el intercambio de información política llegaba a tanto, que el conde-duque de Olivares debatía en el Consejo de Estado cómo poder terminar con esto. Alejandra Franganillo Álvarez nos muestra este fenómeno como parte de la red epistolar de la gran duquesa María Magdalena de Austria. La autora evidencia con ella una gran red de mujeres pertenecientes a la Casa de Austria que se conectaban mediante el envío de cartas y que claramente perseguían fines políticos.

Que la red del Convento de las Descalzas sería duradera en el tiempo nos muestra el capítulo de Silvia Mitchell sobre la reina y regente Mariana de Austria. A través de las monjas mantenía comunicación durante más de diez años con María Teresa, su hijastra y esposa de Luis XIV de Francia. También durante su destierro de la corte, le ayudaban a mantener contacto con su hijo, el rey Carlos II.

El tercer bloque lleva por título "Cartas confidenciales en el entorno familiar de los Habsburgo" y contiene un total de cuatro contribuciones. Tenemos, nuevamente, el caso de la infanta Isabel Clara Eugenia, esta vez con su correspondencia con fray Íñigo de Brizuela, una de las personas de su mayor confianza en el gobierno de Flandes. En otro caso se nos presentan varias mujeres Habsburgo, quienes se correspondían con el padre Marco d'Aviano, con el que discutían temas de primera importancia, tales como la cuestión sucesoria de Carlos II. Finalmente, hay dos casos de mujeres nobles, la duquesa de Villahermosa y la condesa de Harrach, que constituían piezas de las redes epistolares femeninas previamente mencionadas.

Laura Oliván demuestra cómo la condesa se movía entre las cortes de Viena y Madrid a lo largo de su vida y siempre se mantenía informada de lo que pasaba en la otra. Para ello también usaba, por ejemplo, a su propio hijo cuando éste se encontraba en Madrid hacia fines del siglo XVII. Más de un siglo antes era la duquesa de Villahermosa quien funcionaba como nexo en la corte de Felipe II para actuar a favor de los intereses de sus padres Vratislav de Pernstein y María Manrique de Lara, uno de los más emblemáticos matrimonios entre la nobleza hispana con la del reino de Bohemia.

El caso de Marco d'Aviano, presentado por Rocío Martínez López, muestra cómo un fraile se vinculaba con cuatro de las mujeres más importantes de la dinastía Habsburgo de la última parte del siglo XVII y podía de estar forma conversar y opinar sobre los temas de más alta trascendencia para ambas ramas. Todo ello a pesar de la asimetría social que existía entre los correspondientes. Esto mismo también se puede afirmar para la infanta Isabel Clara Eugenia y sus cartas intercambiadas con Íñigo Brizuela. Al fallecer su marido Alberto, Isabel se convirtió de soberana en lugarteniente para su sobrino Felipe IV, lo cual, además, llevó 
al restablecimiento del Consejo de Flandes. La presidencia la ocuparía con Brizuela, una de las personas más cercanas a la infanta, tanto que le resultaba más importante tenerlo en Madrid que con ella en Bruselas. Las cartas evidencian la confianza tanto personal como política que existía entre ambos, especialmente por parte de la infanta, que incluso discutía con Brizuela la más alta política de la corte.

En definitiva, se trata de contribuciones muy valiosas, algunas por tratar cartas hasta ahora prácticamente desconocidas e ignoradas por los historiadores, otras porque dan enfoques e interpretaciones nuevas a correspondencia conocida e incluso editada hace mucho tiempo. Como conclusión general, se evidencia el rol fundamental de las mujeres nobles y de realeza en las redes de novedades e informaciones que circulaban en Europa, especialmente entre las cortes de Viena y Madrid entre las dos ramas de la Casa de Austria. Muchos de estos capítulos pueden ser puntos de partida para investigaciones futuras y más extensas.

\section{Matthias Gloël}

Universidad Católica de Temuco-Chile 